second picture through a yellow glass, the difference between the two almost entirely disappears, as the glass corrects the faults of the picture. The smock of the boy no more appears of that intense blue which we may see in a lady's silk dress, but never in the linen smock of a peasant. It changes into the natural tint we find in the first picture. The purple face of the boy

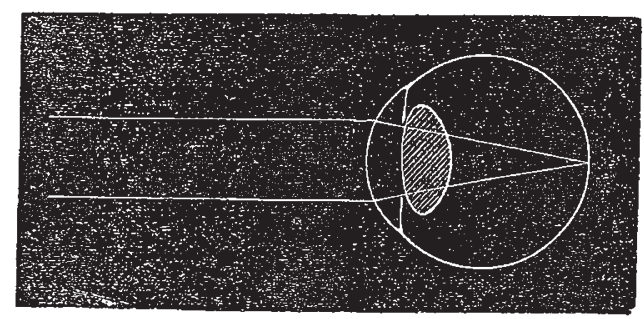

FIG. I

also becomes of a natural colour. The shades on the neck of the girl and the arms of the child, which are painted in a pure blue, look now grey, and so do the blue shadows in the clouds. The grey trunk of the tree becomes brown. Surprising is the effect upon the yellowish green foliage, which, instead of appearing still

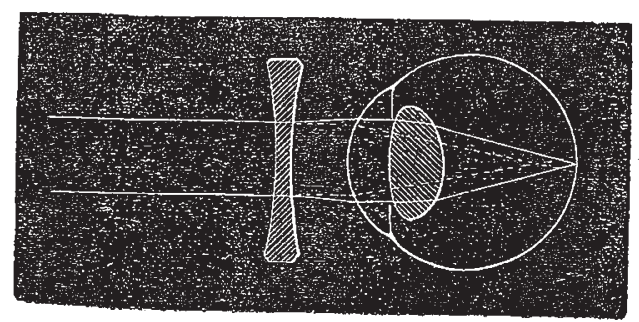

FIG. 2

more yellow, is restored to its natural colour, and it shows now the same tone of colour as the foliage in the earlier picture. This last fact is most important to prove the correctness of my supposition. The endeavour to explain this fact became for me the starting-point of a series of investigations to ascertain the optical qualities of the pig-

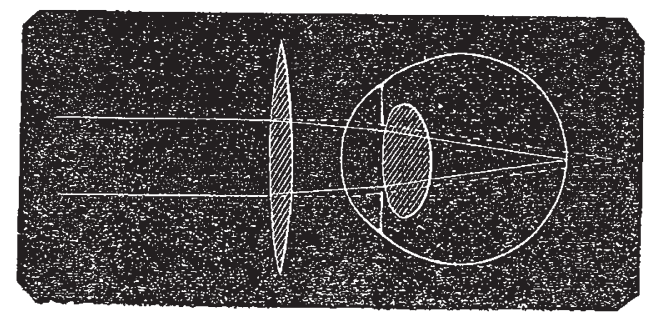

FIG, 3

ments used in painting, and thus to enable us to recognise them by optical contrivances when the vision of the naked eye does not suffice to analyse the colours of a picture.

If it is the dispersion of light which, as in Turner's case, alters the perception of nature, it can be partly rectified by a kind of diaphragm with a small opening (Donder's sthenopeical spectacles).

In cases of astigmatism, the use of cylindrical glasses will completely correct the aspect of nature, as well as of the picture. Certain anomalies in the sensation of colour may also be counteracted to some extent by the use of coloured glasses ; for instance, by a blue glass, when the lens has become yellow, as was the case with Mulready.

If science aims at proving that certain works of art offend against physiological laws, artists and art critics ought not to think that, by being subjected to the material analysis of physiological investigation, that which is noble, beautiful, and purely intellectual would be dragged into the dust. They ought, on the contrary, to make the results of these investigations their own. In this way art critics will often obtain an explanation of the development of the artist, and artists will avoid the inward struggles and disappointments which often arise through the difference between their own perceptions and that of the majority of the public. Never will science be an impediment to creations of genius.

Dr. Liebreich's lecture will appear in extenso in the April number of Macmillan's Magazine.

\section{THE NATURAL HISTORY OF EASTERN THIBET}

R. CAMPBELL, Superintendent of Darjeeling, has recently published a series of valuable papers on Eastern Thibet in The Phonix, a monthly magazine for China, Japan, and Eastern Asia, ably edited by the Rev. James Summers, Professor of the Chinese Language in King's College. As a journal of this kind must naturally have only a limited circulation, and is not likely to be in the hands of many of our readers, we have no hesitation in abstracting from Dr. Campbell's contributions the following notes on the Zoology and Mineralogy of a country that at the present time is of special interest, both in a geographical and a commercial point of view. The following is a list of the animals of Eastern Thibet, the native name being attached to each :-Goa, an antelope ; Gnow, the Ovis ammon; Rigong, the hare; Kiang, the wild ass; Lawa, the nusk-deer; Shano, a large deer, Cervus affinis; Cheu, Antelope Hodgsoni; Dong, the wild yak of Thibet; Pegoo, the yak; A small cow, whose native name is not given; $S a u h$, cross between cow and yak; $B a$ Sauh, produce of female yak by bull; Look, sheep ; Peu Ra, Thibet goat ; Phák, the pig; Cha, the commonfowl; Damjhar, the duck; Damjhar Cheemoo, the goose (besides the duck and goose there are numerous wild fowls, swimmers and waders, which migrate from India in March, and return in October); Chungos, a reddish wild dog; Koong, a mottled civet; Sik, the leopard; Tagh, the tiger; Somb, the bear (a red and a black species); Nehornehu, a large sheep, goat, or antelope of various colours, four feet high, with enormous horns four feet long, sloping backwards, and a tail fifteen inches in length.

This completes Dr. Campbell's list of the indigenous mammals and birds. With regard to the Dong or wild yak of Thibet, he observes that it is the fiercest of all known ruminants, and will rarely allow a man to escape alive if it can come up with him. It is generally hunted on horseback, the great aim being to detach one from the herd. The horns of the full-grown buck are said to be three feet long, and the circumference must be enormous. They are used by the Grandees at marriage and other feasts as gigantic drinking cups, and handed round to the company. The horns so used are finely polished, and mounted in silver or gold and precious stones. A stuffed "Dong" is common in Thibetan Lamaserais, standing in front of the image of Mahákkáli, at whose shrine the animal is thus figuratively sacrificed.

of Look or sheep there are four principal varieties-Ist, Chang Look or northern sheep, very large, with fine wool; flocks of from 400 to 1,000 tended by one man. 2nd. Sok Look, rare, but greatly praised; it is a heavy-tailed sheep, coming from the province of Sok, east of Lassa; wool not very fine. $3 \mathrm{rd}$. Lho Look, a very small sheep 
indeed, generally white but sometimes black, bred about Lassa; wool very fine and like the shawl wool. 4th. Changumpo Look, abundant about Geroo and in Dingcham, generally very large; the white wool very fine and soft. The flesh of all these sheep is fine-grained and good.

Of the $P h a c k$ or pig there are two varieties, the southern pig, which is similar to the Indian village pig, and the small Chinese pig. There are no wild hogs in Thibet. The Chinese butchers at Lassa blow their pork so as to give it a deceptively fine appearance.

Ducks and geese are not eaten by the Thibetans, but are greatly used by the Chinese, for whom they are specially bred in Lassa.

The lakes of Thibet are full of fish, of which only one kind, named Choolap, is described; it grows to the weight of $81 \mathrm{~b}$., and is a coarse food. It is, however, caught and preserved largely; the fish being gutted, split up, the tail put in the mouth, and dried, without salt, in the open air. Thus prepared they will keep for a year. The mode of catching them is singular; when the lakes are frozen over, a hole is made in the ice, to which they rush in such abundance that they are pulled out by the hand.

There are no leeches or mosquitoes in Thibet, nor are maggots or fleas ever seen there; and in Dingcham or Thibet Proper there are no bees or wasps.

Dr. Campbell gives us some very interesting information regarding the food of the Thibetans. During the summer months they use very little fresh meat. They do not like it boiled, and are not partial to it raw, unless it has been dried. In November there is a great slaughter, and a wealthy man, who has perhaps 7,000 sheep, will kill 200 at this time for his year's consumption. The animal after being killed is skinned and gutted and then placed on its feet in a free current of air. In a couple of days it becomes quite hard and is then ready for eating. It is kept in this way for more than a year without spoiling, even during the rainy periods. When long exposed to the wind of Thibet it becomes so dry that it may be rolled into powder between the hands. In this state it is mixed with water and drunk, and used in various other ways. The Thibetans eat animal food in endless forms, and a large portion of the people live on nothing else. The livers of sheep and other animals are similarly dried or frozen, and are much prized, but to strangers they are very distasteful for their bitterness and hardness. The fat is dried, packed in the stomachs, and then sent to market or kept for home use.

With regard to edible vegetables, it is stated that wheat, barley, and buckwheat sown in April or May and irrigated, are reaped in September, barley in Thibet taking the place of potatoes in Ireland, four-fifths of the population living on it. Besides these, the other crops are composed of peas, turnips, and a little mustard. The grain is ground in water mills. The bread is all unleavened, and cooked on heated stoves or gridirons. The sweet pure farinaceous taste of the fine flour equals the best American produce. The staple food of the country is champa, called suttoo in India; it is finely-ground flour of toasted barley. It is much eaten without further cooking; mixed up with hot tea it is called paak, and when prepared with tepid water it is known as seu. If any of our readers wish to enter upon "pastures new" in the breakfast department, they may try Tookpa, which, to be properly appreciated, should be taken at daybreak before any matutinal ablutions. It is a sort of broth made with mutton, champa, dry curds, butter, salt, and turnips.

Goats are also reared in considerable flocks, but for their milk rather than their flesh. The milk of yaks, cows, sheep, and goats is used alike for making dried curds and the various preparations of milk used by these people. Mares' milk is not used in Eastern Thibet.

We now proceed to notice the mineral wealth of this remarkable country.
Pen, a carbonate of soda, is abundant south of the Yaroo; it appears in a whitish powder on the soil, never in masses underground. It is not used for soap-making or otherwise in the arts, but is always put into the water when tea is made, and is much employed medicinally.

Chulla, borax, is only obtained north of the Yaroo, whence it is imported to other parts of Thibet, to India, viad Nepaul, Sikkim, and Bootana, and thence to Calcutta and Europe.

Sicha, saltpetre, is abundantly manufactured in the Cara Thibetan sheep folds, where composts of sheep's dung and earth are found to produce it.

Lencha, common salt, occurs in commerce in three forms, viz. : Sercha, white and best; Cháma, reddish and good; and Pencha, yellowish and bad, containing soda or magnesia and earthy matter. All the salt used in Eastern Thibet is the produce of the lakes and mines north of the Garoo, or comes from Lache, a district between Digarchi and Ladak. According to the best information, all the salt is the produce of lakes, while some assert that it is dug out of the earth. It is certain that the salt-producing districts are all but inaccessible, and can only be traversed by men and sheep; and that their elevation prevents the working from being carried on except in the warmer part of the year, from April to November. Thousands of sheep are employed in carrying the salt to places accessible to yaks, the former animals carrying a load of $201 \mathrm{~b}$. to $24 \mathrm{lb}$. on open places, or of 8lb. to Iolb. in the rugged vicinity of the deposits, whose elevation is not less than 22,000 feet, while the latter are capable of bearing a load of $I 60 l b$.

Ser, gold, is found in the sands of a feeder of the Garoo, on its northern side, but the name of the river could not be ascertained by Dr. Campbell. The Garoo itself does not yield any gold washings. Most of the gold of Thibet is the produce of mines or diggings.**

Pabea, the yellow arsenic of commerce, is found west of Lassa, near the borders of China.

There are no mines of iron, silver, copper, quicksilver, lead, or coal in Thibet; the latter substance is, however, imported from China.

The turquoise, real or artificial, is universally worn in rings, necklaces, \&c., and large, amber-like beads are a favourite ornament; but it is uncertain whether they are natural products of Thibet. The latter are apparently composed of turpentine mixed with some hardening material. Numerous imitations of turquoise are imported from China; and real but not valuable stones are sent, vid Cashmere (but from what locality is not stated). The only test of a real stone that is resorted to by the Thibetans is to make a fowl swallow it; if real it will pass through unchanged.

In conclusion, we may add that Dr. Campbell's articles in The Phonix contain much valuable matter on the geography, the government, and army of Thibet, the personal habits, customs, and ceremonies of the Thibetans, their religious festivals, the seasons, soil, and agriculture of the country, the wages of labour, and the most prevalent diseases. Amongst "Things not generally known," we may mention Goomtook, or The laughing disease, which consists of violent fits of laughter with excruciating pain in the throat. It equally attacks men and women, and often proves fatal in a few days.

\section{ON THE CAUSE OF FIXED BAROMETRIC VARIATIONS}

$T H E$ chief difficulty in the way of explaining the annual and diurnal variations of the barometer by the heating and cooling of the air, appears to be the existence of a double maximum and minimum. To show how such a double maximum and minimum might result from the

* Notices of the Thibetan Gold Mines may be found in several recent numbers of the "Proceedings of the Royal Geographical Society." 